\title{
Role of Stress on Women's Health: Causes and Prevention
}

\author{
Razia Saleem $^{1}$, Shamsul Siddiqui ${ }^{2}$
}

\section{ABSTRACT}

In recent years, stress has been the focus of intense research attention. Stress is a misfit between the demands of the environment and the individual's abilities; the imbalance may be corrected, according to the situation, either by adjusting external demands to fit the individual or by strengthening the individual's ability to cope or both. Everyone is exposed to stress, and a great number of people have experienced the traces of stress. Women are socialized to be the caretakers of others. More women than men have both a career outside the home and continue to try to juggle traditional responsibilities after hours. It has often been shown that women are the worriers and often do not make time to manage their health and take care of themselves. Stress is on the rise for women as they struggle to find a balance between their homes and careers. The recession has caused a greater need for women to work outside of the home to support their families. Health is a general condition of the body or mind with reference to soundness and vigor; it will be reflected by good or poor health. A poor health affects our mind, as a stressed life affects our health. The struggle that women confront each days trying to achieve the standards of being a daughter, women, wife, mother, house, and/ or career keeper puts us in a vulnerable position of presenting stress effects that may affect our health. And there are some preventive measures to cope with stress such as meditation, yoga, quality time etc.

Keywords: Stress, Women's health, Causes and prevention, Meditation and yoga.

Life is full of stressors that produce threats to our well -being. Psychologist believe that daily life involves a series of repeated sequences of perceiving a threat, considering ways of coping with it, and ultimately adapting to the threat, with greater or lesser success (Gatchel \& Baun,1983). Stress is a process by which events threaten or challenges individual's ability to deal adequately to the situation. Both the present and unpleasant events can produce stress. The pleasant events- such as marriage, planning a party, joining the school or job; and the unpleasant events- family problems, examination, experiencing circumstances at the work place - produces threat to our well-being. Although negative events result in greater detrimental effects than

\footnotetext{
${ }^{1}$ Research Scholar, Department of psychology, AMU, Aligarh, India

${ }^{2}$ Research Scholar, Department of psychology, AMU, Aligarh, India

*Responding Author

(C) 2016, R Saleem, S Siddiqui; licensee IJIP. This is an Open Access Research distributed under the terms of the Creative Commons Attribution License (http://creativecommons.org/licenses/by/2.0), which permits unrestricted use, distribution, and reproduction in any Medium, provided the original work is properly cited.
} 


\section{Role of Stress on Women's Health: Causes and Prevention}

positive ones, ( Sarason et.al 1978). There are certain kinds of events such as the death of a loved ones, participation in combat during a war or natural disasters are almost universally stressful, other situation may or may not be stressful to a particular person (Fleming, Baum \& Singer; 1984; Lazarus\& Cohen, 1977). Stress is a misfit between the demands of the environment and the individual's abilities, the Imbalance may be corrected Stress is a necessary and unavoidable of daily living--necessary because without some stress we would be listless and apathetic creatures, and unavoidable because it relates to any external event, be it pleasurable or anxiety producing. A person's response towards according to the situation, either by adjusting external demands to fit the individual or by strengthening the individual's ability to cope, or both. At this point, it should be borne in mind that since stress is multifaceted phenomenon, no simple solution is available.

Furthermore, differences in the particular circumstances of each case make it impossible to provide a unique solution for the management of stress. In general, and regardless of their differences, publications conclude that the ideal solution to combat stress is to prevent its occurrence. This may be achieved by tackling the core of the problem - the cause. However, there is no single cause of stress and the Elimination of all stressors is a utopian task. Therefore, action should be aimed at eliminating as many causes as Possible, so that the action taken reduces stress and prevents future stress. As this cannot always be achieved in the Short term, it is generally agreed that improving the ability to cope with stress is a valuable strategy in the process of Combating stress. The manual can then go on to identify a series of essential steps for the prevention of stress. These include: stress recognition, stress assessment, anti-stress intervention, monitoring and evaluation. Stress is everywhere, but as a relatively new phenomenon. How can we define it and how can we explain its extraordinary cost to both business and government? The suffering induced by stress is No figment of the imagination but can we accurately examine the relationship between stress and ill-health.

Most women do not have responsibility only in one domain anymore; they have to balance the competing demands of both work and family domains (Biçaksiz, 2009). Work and family are the two most important aspects in women's lives. Balancing work and family roles has become a key personal and family issue for many societies. There are many facets in working mother's lives that subject to stresses. They deal with home and family issues as well as job stress on a daily basis. Imbalance between work and family life arises due to a number of factors. Various factors appear to strengthen the brunt of pressure on women. The question was raised whether there is a relationship between occupational stress and family difficulties of working women.

Stress depends on whether an event is appraised as a challenge or a threat (Lazarus \& Folkman, 1984). Balancing work and family roles has become a key personal and family issue for many societies. Work and family are the two most important aspects in people's lives and, contrary to 


\section{Role of Stress on Women's Health: Causes and Prevention}

the initial belief that they are distinct parts of life; these domains are closely related (Ford et al., 2007).

An Although much has been made of the different ways that men and women respond to stress ("fight or flight" vs. "tend and befriend"), there are also substantial discrepancies in how stress impacts women's health as compared to men's. Studies have found that women differ from men not only in their emotional responses to stress, but also that acute and chronic stress may take a greater toll on women's' physical and mental health's. When reacting to stressors, the body releases hormones such as cortisol, which is known to impact the immune system, digestive system, skin and more -- and cortisol responses to psychological stress have also been shown to differ between men and women. Stress can affect nearly every system in the body, and it may be undermining your health in more ways than you realize. Scroll through the list below for 10 physiological and cognitive effects of stress on women's health.

There are so Women are socialized to be the caretakers of others. More women than men have both a career outside the home and continue to try to juggle traditional responsibilities after hours. Over $70 \%$ of married women with children under the age of 18 are employed outside the home. Sociologists describe women as struggling to achieve the "male standard" at work, while trying to maintain the perfect wife and mother standards at home.

Women are also less likely to be in as powerful positions as men to change their environment. Women find it harder to say no to others' requests and often feel guilty if they can't please everyone. They often spend less time nurturing their own emotional and physical needs, as that might be perceived as selfish. In me preventive measures to cope with stress such as meditation, yoga, quality time etc.

Hochschild (1997) estimates, based on major time-use studies, that woman in dual career families work an extra month of 24 hour days each year compared to men. This extra time is spent on what she terms "second shift" work, work outside paid employment such as housework, home management, and childcare. Together, these studies suggest that managerial women may experience more stress than men and that the sources of stress are gender-related; that is, related to the expected and actual roles of women in society, and to the fact that, despite progress, executive women still occupy minority status in organizations. There are some stressors, however, that may be particularly important for working women.

Stress is a normal part of life. Many events that happen to you and around you -- and many things that you do yourself put stress on your body. You can experience stress from your

environment, your body, and your thoughts. Women are feeling it more acutely than ever. After decades of making progress in the work force, many women are feeling less valued than men, according to a recent APA survey on Stress in the Workplace. They're feeling they don't receive

(C) The International Journal of Indian Psychology, ISSN 2348-5396 (e) | ISSN: 2349-3429 (p) | 120 


\section{Role of Stress on Women's Health: Causes and Prevention}

adequate monetary compensation for their work and feel that employers offer them fewer opportunities for internal career advancement than men.

Women's exacerbating the realities of the stressors in the job market, women may be more likely to internalize stress, according to a recent article in the Wall Street Journal. They may hesitate to speak up for themselves or to challenge behavior that they see as unfair. And, according to the APA survey, men are more likely than women to use flexible work arrangements, although both men and women report that job demands interfere with their ability to fulfill family or home responsibilities.

In the short term, stress isn't always a bad thing. It can motivate us to deal with a situation that poses some level of threat. And the burst of adrenaline and other hormonal changes that occur during a stress response can heighten our senses and give us extra amounts of energy.

But chronically stressful situations that go unaddressed can lead to serious health problems. Constant job stress can impact eating and exercise habits, which can contribute to high blood pressure, high cholesterol and weight gain. Stress on the job can also accelerate the onset of heart disease and can lead to burnout, which is often associated with depression.

There are a number of strategies for dealing with workplace stress. What will work for you may be entirely different than what will work for others. Some interventions include:

- $\quad$ Learning relaxation and meditation techniques

- $\quad$ Assertiveness training

- $\quad$ Nutrition and exercise counseling

- $\quad$ Time management training

- $\quad$ Structuring breaks into your workday

- $\quad$ Emotion regulation training

- Identifying and setting reasonable standards

Options for decreasing your stress levels include: making changes to yourself how take care of yourself and how you think about and respond to stress and making changing to your work environment by doing things such as asserting your needs and managing your time. It's important to remember that sometimes, despite our best efforts, we are powerless to make changes to our environment. Some work demands won't change and sometimes we're unable to change a hostile work environment. When that is the case, to reduce your stress, you may have to evaluate your career options.

Family stress theory can be applied to critical work events that negatively affect the family, such as job loss and to chronic work stressors such as role overload, instability, job dissatisfaction, inadequate child care and shift work. 'Families' and 'employment' are inter-related and socially

(C) The International Journal of Indian Psychology, ISSN 2348-5396 (e)| ISSN: 2349-3429 (p) | 121 


\section{Role of Stress on Women's Health: Causes and Prevention}

constructed. The Functionalist theory of the 'modern' (or 'standard') Current Research in Psychology 1 (2): 75-81, 201076.

There are many facets in working mother's lives that subject to stresses. They deal with home and family issues as well as job stress on a daily basis. Imbalance between work and family life arises due to a number of factors. Various factors appear to strengthen the brunt of pressure on women. Frequently household duty involves protecting family members: children, the sick and the elderly. Even where men play role in the caring function, usually it is the woman who is the initial career, although she may suffer additional health risks. 'Work-family spillover' is result of the performing multiple roles and this will be accused when the demands from family and home life, interfere with women's ability to perform effectively in the workplace. Having to juggle multiple roles and effect of the pressures from work on one's attitude and behavior within the family also may lead to 'work-family spillover' (Younkin, 2010). A number of problems that working mothers can face: Difficulties with finances, Getting to spend time with the kids, Keeping on top of the housework, Dealing with sickness, Quality time for yourself, Personal illness and stress. Several researches have indicated that work-family difficulties can make negative influence for individual mentality and physiology.

In today's harried world, it is not uncommon for women to wear many hats in their families. Statistics show women are more often than men tasked with care giving responsibilities for both children and family members inside their home.

As health care decision makers and often caregivers for their families, women tend to put others' needs before their own. With so many competing responsibilities, women often don't take time for themselves and their overall wellness can be compromised. It is vitally important that women give themselves a break and find healthy ways to manage stress and live well. Healthy lifestyle strategies for busy women, mothers and caregivers:

Take care of yourself — set aside time to engage in healthy activities that you enjoy or that help You relax. Identify hobbies, increase exercising or eating healthy foods. Making time for yourself

Will help you better manage stressful situations and allow you to better care for the whole family.

Also, find something that makes you laugh - humor is important, and laughter can really make life a whole lot easier.

- Recognize how you deal with family stress - some people deal with stress by engaging in Unhealthy behaviors, such as smoking, drinking, comfort eating, or yelling and becoming irritable. Remember that stress is inevitable. What makes the biggest difference is how you manage that Stress. 


\section{Role of Stress on Women's Health: Causes and Prevention}

Reach out to others: Enlist and accept help from others including friends and family. Identify Ways your family can help with specific needs that must be met like providing a meal or Babysitting so you can find time to take a break and rejuvenate. Take time to connect with your Girlfriends when you are feeling overwhelmed. Strong female friendships can help women Overcome stressors.

Keep things in perspective: remind yourself that each morning offers a new start and take Things one step at a time. Realize that there is no one perfect way to parent. Staying optimistic Lowers stress.

Prioritize: you can only do one thing at a time. Delay or say no to the unimportant tasks, and make appointments for more important tasks, such as spending quality time with a spouse Or Child.

Be organized: Keeping the family and yourself organized reduces stress. Put family health Information in separate folders; get family members to keep laundry in color coded baskets; keep Book bags in assigned bins. Harried searching for things adds to mom's stress. Enlist your Children's help in developing an organization plan for your household - if they are involved in the Planning, they will be more likely to follow through.

Ask for professional help: if you feel overwhelmed by stress or the unhealthy behaviors you Use to cope; you may want to talk with a psychologist who can help you address the emotions Behind your worries, better manage stress and change unhealthy behaviors.

\section{CONCLUSION}

Balancing work and family roles has become a key personal and family issue for women. Working women and Family studies specialists find that the changing family structure is a major source of stress and role strain in both the work place and the home. Women need to feel that their work is important and essential and that they are not sacrificing their child's well being in order to benefit themselves.

There is another dilemma for working women; they always feel that home is their original domain, which they have to sustain in all circumstances. Women usually have a feeling of guilt for sparing less time for their maternal responsibilities and family. This dual responsibility proves the double burden on her and that makes her to fight concurrently on two fronts. Sources of work stress, including role ambiguity, Relationships, tools and equipment, lack of autonomy, career advancement, job security, workload and work/home interface have been implicated in affecting family functioning. Though men are increasingly contributing to family responsibilities, women still provide more than their fair share of care giving responsibilities at home. Current Research in Psychology 1 (2): 75-81, 201080 if women are working they suffer more between their family and job and they found more imbalance between work and family than nonworking this imbalance create stress in their life because of this stress these women's 


\section{Role of Stress on Women's Health: Causes and Prevention}

face more mental and physical problems so the preventions is very important for them because the women's play very important role at home and also outsides of home nowadays.

\section{Acknowledgments}

The author appreciates all those who participated in the study and helped to facilitate the research process.

\section{Conflict of Interests}

The author declared no conflict of interests.

\section{REFERENCE}

Biçaksiz, P., 2009. The effects of gender role ideology, role salience, and role demands and core self - evaluations on work-family interface. Msc. Thesis. Middle East Technical University. Canadian Psychological Association; "psychology works factsheet" managing stress for family responsibilities- for women. Current Research in Psychology 1 (2): 75-81, 201076.

Fleming, R., Baum, A., \& Singer, J.E (1984). Toward an integrative approach to a study of stress. Journal of personality and social psychology, 46 939-949.

Ford, M.T., B.A. Heinen and K.L. Langkamer, 2007. Work and family satisfaction and conflict: a Meta analysis of cross-domain relations. J. Applied Psychol., 92: 57-80. DOI: 10.1037/0021 9010.92.1.57.

Gatchel, R.J., \& Baum, A. (1983). An introduction to health psychology. Reading M.A: Addison- Wesley.

Hochschild, A. R.: 1997, The Time Bind (Metropolitan Books, New York).

Lazarus, R. S., \& Folkman, S. (1984). Stress, Appraisal and Coping. New York: Springer. Maryam Zarra-Nezhad, 1Ali Moazami-Goodarzi, 2Leila Hasannejad and 2Khadijeh Roushani 11Young Researchers Club, Islamic Azad University of Ahvaz, Ahvaz, Iran. 2Department of Psychology, Faculty of Social Science, Islamic Azad University, Ahvaz Branch, Iran.

Sarason, I.G. Johnson, J.H \& Sigel J.M. (1978). Assessing the life of impact changes : Development of the Life Experiences Survey. Journal of consulting and clinical psychology, 46, 932-946.

Younkin, F.L., 2010. Work-family spillover, division of labor and relationship satisfaction. MSc. Thesis. Ohio State University

How to cite this article: R Saleem, S Siddiqui (2016), Role of Stress on Women's Health: Causes and Prevention, International Journal of Indian Psychology, Volume 3, Issue 4, No. 64, ISSN 2348-5396 (e), ISSN: 2349-3429 (p), DIP:18.01.127/20160304, ISBN: 978-1-365-32519-9 